\title{
Coating Lacticaseibacillus rhamnosus GG in Alginate Systems: an Emerging Strategy Towards Improved Viability in Orange Juice
}

\author{
Angela Bonaccorso, ${ }^{1}$ Nunziatina Russo, ${ }^{2}$ Alessia Romeo, ${ }^{1}$ Claudia Carbone, ${ }^{1}$ Maria Aurora Grimaudo, ${ }^{3}$ \\ Carmen Alvarez-Lorenzo, ${ }^{3}$ Cinzia Randazzo, ${ }^{2}$ Teresa Musumeci, ${ }^{1,4}$ (1) and Cinzia Caggia ${ }^{2}$
}

Received 21 January 2021; accepted 16 March 2021

\begin{abstract}
Fruit juices are successfully proposed as suitable probiotic vehicles, but researchers' efforts should be developed to avoid effects of bacteria overgrowing on sensory and nutritional cues of final products and to preserve viability of probiotic bacteria during storage. In the present study, encapsulation of Lacticaseibacillus rhamnosus GG strain in alginate systems was performed through ionotropic gelation technology. The alginate systems were optimized by using Box-Behnken Design to investigate the influence of three independent variables at three different levels: particle mean size and polydispersity index. The optimized probiotic-loaded alginate particles were added to orange juice samples. The viability of the probiotic strain, both as free and microencapsulated, was evaluated in orange juice stored at $5^{\circ} \mathrm{C}$ for 35 days. Morphology and size of probiotic-loaded alginate particles were found suitable for incorporation into juice. TEM analysis revealed that unloaded systems were clustered as nanoparticles (CL_NP), while the loaded sample appeared as a coated system (Coated_LGG). Microbiological evaluation revealed that the encapsulation assured the survival of Coated_LGG, with a reduction of less than 1-unit log in cellular density after 35 days of refrigerated storage in orange juice. Results indicated that the encapsulated bacteria did not affect the macroscopic properties neither the microbiological characteristic of orange juice; thus, it can be proposed as functional food.
\end{abstract}

KEY WORDS: probiotics; lactobacillus encapsulation; experimental design; alginate polymer; functional food.

${ }^{1}$ Department of Drug Sciences and Health, University of Catania, Via Santa Sofia, 64, 6, 95125, Catania, Italy.

${ }^{2}$ Department of Agriculture, Food and Environment (Di3A), University of Catania, Via Santa Sofia 100, 95123, Catania, Italy.

${ }^{3}$ Departamento de Farmacología, Farmacia y Tecnología Farmacéutica, I+D Farma Group (GI-1645), Facultad de Farmacia and Health Research Institute of Santiago de Compostela (IDIS), Universidade de Santiago de Compostela, 15782, Santiago de Compostela, Spain.

${ }^{4}$ To whom correspondence should be addressed. (e-mail: teresa.musumeci@unict.it)

Abbreviations: $B B D$, Box-Behnken Design; $B S$, Backscattering; $C F U$, Colony-forming unit; $C L \_N P$, Cluster of nanoparticles; Coated_LGG, Coated Lacticaseibacillus rhamnosus GG; CPPs, Critical process parameters; $C Q A s$, Critical quality attributes; $C T R L$, Control; $D L S$, Dynamic light diffusion; $D o E$, Design of the experiment; $E D L$, Electric double layer; $L A B$, Lactic acid bacteria; $L G G$, Lacticaseibacillus rhamnosus GG; MCs, Microcapsules; NPs, Nanoparticles; PCS, Photon correlation spectroscopy; PDI, Polydispersity index; $Q T T P$, Quality target profile; $S D$, Standard deviation; $T$, Transmission; TEM, Transmission electron microscopy; TSI, Turbiscan Stability Index; TSS, Total soluble solids; ZP, Zeta potential.

\section{INTRODUCTION}

Over the past decade, there was a growing consumer interest in modern food products capable of performing therapeutic and curative features. There is a consistent rise in the demand for functional foods supplemented with probiotics, which are known to improve human health apart from the native nutritional value (1). Probiotics are living microorganisms that, when administered in adequate amounts, confer beneficial effects to the host (2). The health effects of probiotics are strain-specific and dose-dependent (3). Recently, non-dairy products have been considered as an alternative for consumers who are lactose intolerant, allergic to milk proteins, hypercholesterolemic, or strictly vegetarian (3). Consequently, several fermented vegetables or fruitbased products $(4,5)$ are being proposed and forecasted to take a large share of the global market, representing one of the main challenging strategy for food industry $(6,7)$. Fruits and vegetables have been proven to support the survival of probiotics, thanks to their high sugar and total antioxidant content and relatively low $\mathrm{pH}$ values. In fruit juices, probiotic cultures could be added as biomass $(8,9)$ or through direct addition of lyophilized cultures (10). However, these methods 
besides being time consuming, requiring specific equipment (as refrigerated centrifuges) and specialized operators (8), can reduce the microbial viability and impair sensory properties (11-13). Moreover, it is well-known that to obtain a temporary colonization of the intestine "the minimum density of required probiotic is at least 1 billion live cells per strain per day" $(3,6,14)$. In order to overcome the aforementioned disadvantages and to guarantee such a high concentration, microencapsulation can be exploited as a promising strategy $(11,15)$.

Microcapsules (MCs) consist of a core containing active ingredients and a polymeric shell, acting as a protective membrane able to regulate substances exchange in and out (15). Polymers of natural origin are mostly used for probiotic microencapsulation $(12,13)$; among them, alginate is the most extensively used to microencapsulate lactobacilli and bifidobacteria (16). The choice of the adequate preparation method of MCs depends on several factors such as physicochemical properties of the selected materials, desired particle size, and release pattern. Among the described methodologies, the ionotropic gelation technique allows to obtain microparticles under mild conditions; as an example, an alginate solution is usually dripped into a crosslinking solution consisting of $\mathrm{Ba}^{+}, \mathrm{Ca}^{2+}$, and $\mathrm{Sr}^{2+}$ salts (16). When the bivalent cation comes into contact to alginate chains, interchain bonds are established generating a threedimensional polymeric network, defined as "egg-box" like for the characteristic shape of the supramolecular structure (17).

The aim of the present study was to design alginatebased particles suitable for loading Lacticaseibacillus rhamnosus GG cells into fruit juices with multivariate approach of quality by design using Box-Behnken Design (BBD) $(18,19)$. The critical quality attributes (CQAs) and the critical process parameters (CPPs) were selected from the knowledge space through literature analysis of the last 10 years (PubMed sources) (20-22). In order to optimize the formulation, the quality target profile (QTTP) was defined. The effect of three independent variables was investigated at three different levels on particle mean size and polydispersity index (PDI). The optimized alginate system was loaded with Lacticaseibacillus rhamnosus GG $(23,24)$, and their behavior was investigated in low-pH juices. Moreover, the viability of the probiotic strain, both as free and microencapsulated, was evaluated in orange juice stored at $5^{\circ} \mathrm{C}$ for 35 days.

\section{MATERIALS AND METHODS}

\section{Materials}

Sodium alginate (20-40 kDa), sunflower oil from Helianthus annuus, and Span 80 were purchased from Aldrich S.r.l. (Milan, Italy). Calcium chloride was obtained from Riedel-de-Haën (Hannover, Germany). Deionized water was used for all preparations. Sicilian $100 \%$ blood orange juice ( $\mathrm{pH} 3.05)$, with no added sugar o preservatives, was kindly provided by the Oranfrizer Company (Scordia, Sicily).

\section{Preparation of Probiotic Culture Cells}

L. rhamnosus GG (LGG), belonging to the Department of Agriculture, Food and Environment (Di3A, University of Catania) was cultured in MRS broth medium (Liofilchem, Italy) and anaerobically incubated at $37^{\circ} \mathrm{C}$ for $18 \mathrm{~h}$. The cells were harvested by centrifugation (BagMixer, Interscience, France) at $4500 \times g$ for $10 \mathrm{~min}$ at $4^{\circ} \mathrm{C}$. The pellets were washed twice with phosphate-buffered saline (PBS, $\mathrm{pH}$ 6.8) and collected by centrifugation as above. The obtained washed pellets, at a final cell concentration of approximately of $10^{10}$ colony-forming unit $/ \mathrm{mL}(\mathrm{CFU} / \mathrm{mL})$, were refrigerated and immediately transferred to the Laboratory of Drug Delivery Technology for further treatments.

\section{Design of Experiment (DoE)}

The optimization of formulation variables was carried out using BBD. The experimental design was generated using the Design-Expert software (7.0.0, Stat-Ease Inc., Minneapolis, MN). Response surface quadratic model was performed for the optimization of formulation variables and the evaluation of the optimum level of each factor.

Three independent variables at three coded levels were selected (Table I): span 80 concentration $\left(X_{1}\right)$, alginate concentration $\left(X_{2}\right)$, and the aqueous to oil phase $(\mathrm{A} / \mathrm{O})$ ratio $\left(X_{3}\right)$. The coded variables $X_{1}, X_{2}$, and $X_{3}$ correspond to $A, B$, and $C$, respectively, within the equations provided by the software. In accordance with the design, 17 formulations were prepared, and the effect of each factor was studied on the particle size $\left(Y_{1}\right)$ and PDI $\left(Y_{2}\right)$ of the formulation as response variables. The experiments were randomized to avoid experimental bias. Three-dimensional (3D) response surface graphs were generated for diagrammatic depiction of values of response. Statistical analysis was performed by using the ANOVA software.

\section{Alginate-Based System Optimization}

Formulation optimization was performed using the "desirability tool," provided by the Design-Expert ${ }^{\circledR}$ (7.0.0, Stat-Ease Inc., Minneapolis, MN) software. This is a method for simultaneous optimization of dependent variables, which permits the calculation of an objective function, and results are obtained with values ranging from 0 (undesired response) to 1 (a fully desired response). The levels of all independent variables are then automatically combined to identify the optimal

Table I. Factors and the Corresponding Levels Investigated During the Box-Behnken Design

\begin{tabular}{lll}
\hline Coded Factors & Coded levels & \\
\cline { 2 - 3 } & Low & High \\
\hline$X_{1}:$ span conc $(\% \mathrm{w} / \mathrm{v})$ & 0.1 & 0.5 \\
$X_{2}:$ alginate conc $(\% \mathrm{w} / \mathrm{v})$ & 0.5 & 2 \\
$X_{3}: \mathrm{A} / \mathrm{O}(\mathrm{v} / \mathrm{v})$ & $1: 20$ & $1: 6$ \\
\hline
\end{tabular}


conditions within the experimental domain. The desirability for a given combination of variables is calculated as the geometric mean of all individual desirability for each response.

\section{Preparation of Alginate-Based System by Ionotropic Gelation}

The alginate-based particles were prepared by the ionotropic gelation method. Briefly, sodium alginate (Table I, from 0.5 to $2.0 \% \mathrm{w} / \mathrm{v}$ ) was dissolved in deionized water. The aqueous phase was added dropwise to a sunflower seed oily phase containing different concentration of Span 80 (Table I), under magnetic stirring (1000 $\mathrm{rpm})$. The two phases were mixed in different ratios, according to the experimental design, and then maintained on a magnetic plate under constant stirring. To obtain a double water-in-oil-in-water emulsion $(\mathrm{W} / \mathrm{O} / \mathrm{W})$, a given volume of the above-described emulsion was added under constant stirring dropwise to the same volume of calcium chloride solution $(0.45 \mathrm{M})$. At the end of the procedure, the double emulsion was maintained for $30 \mathrm{~min}$ at room temperature. The obtained alginate-based particles were purified through centrifugation $(5000 \mathrm{rpm}$ for $30 \mathrm{~min}$ at $6^{\circ} \mathrm{C}$ ), using a Thermo Scientific SL16R centrifuge (Thermo Fisher Scientific Inc., MA, USA). The supernatant was discarded, and the particles collected with deionized water on filter paper and washed with water. Finally, particles were weighed and re-suspended in $10 \mathrm{~mL}$ of deionized water and analyzed using photon correlation spectroscopy (PCS).

\section{Particle Size Distribution and Zeta Potential Measurements of Alginate-Based Systems}

PCS was applied to evaluate mean size, PDI, and ZP of alginate-based particles in suspension, using a Zetasizer Nano S90 (Malvern Instrument, Malvern, UK). The cuvette containing the dispersions was illuminated by a $4 \mathrm{~mW} \mathrm{He}-\mathrm{Na}$ laser beam with a light source (633-nm wavelength). The ZP values were determined at $25^{\circ} \mathrm{C}$. All measurements were performed in triplicate, and the results expressed as mean \pm standard deviation (SD).

\section{Preparation of Optimized Alginate-Based Particles Loaded with Lacticaseibacillus rhamnosus GG Cells}

The optimized formulation (CL_NP) suggested by BBD was composed as follows: $X_{1} 0.42 \% \mathrm{w} / \mathrm{v} ; X_{2} 2 \% \mathrm{w} / \mathrm{v} ; X_{3} 1: 20$ $\mathrm{v} / \mathrm{v}$. The probiotic-loaded alginate-based particles were prepared using the same procedure, wherein the bacterial cells (9.11 $\log _{10} \mathrm{CFU} / \mathrm{mL}$ ) were added in lyophilized form to the sodium alginate aqueous phase (probiotic final concentration $1 \% \mathrm{w} / \mathrm{v}$ ) before the preparation of the primary emulsion. The obtained Coated_LGG particles were freeze dried using an Edwards Modulyo freeze dryer (Thermo, Waltham, MA, USA) for $24 \mathrm{~h}$ at 2 mbar to produce the dry powder. The resultant lyophilized Coated_LGG particles were resuspended in distilled water or Sicilian $100 \%$ blood orange juice $(\mathrm{pH} 3.05)$, to characterize the optimized probiotic-loaded alginate-based particles or for stability and viability tests, respectively.

\section{Transmission Electron Microscopy}

The Lacticaseibacillus rhamnosus GG cells, empty optimized alginate-based particles (CL_NP), and optimized alginate-based particles (Coated_LGG) were subjected to morphological analysis. The transmission electron microscopy (TEM) analysis was performed using a high-resolution microscope JEM-1011 (JEOL USA Inc., Peabody, MA, USA). The pellet of alginate-based particles was resuspended into $10 \mathrm{~mL}$ of distilled water, and an aliquot was placed on carbon-coated grids. After the addition of few drops of phosphotungstic acid, the samples were dried before observation.

\section{Stability Evaluation}

The stability of empty (CL_NP) and loaded particles (Coated_LGG) was evaluated resuspending the pellets into orange juice. The fruit juice without any addition was used as control (CTRL).

Each sample was subjected to mean size, PDI, ZP (Zetasizer Nano S90, Malvern Instrument, Malvern, UK), and $\mathrm{pH}$ evaluation ( $\mathrm{pH}$-meter Mettler Toledo, Columbus, $\mathrm{OH}, \mathrm{USA}$ ) after $5 \mathrm{~h}$ of storage at 25 and $5^{\circ} \mathrm{C}(\mathrm{T} 0)$ and after 1 week of storage at the same temperatures. Measurements were performed in triplicate and results expressed as the mean \pm SD.

Stability was also monitored for 1 week through Turbiscan ${ }^{\circledR}$ Ageing Station (TAGS, Formulaction, L'Union, France) by placing each sample $(20 \mathrm{~mL})$ in a cylindrical glass cell positioned in the Turbiscan ${ }^{\circledR}$ at $25^{\circ} \mathrm{C}$. The detection head was composed of a pulsed near-infrared light source $(880 \mathrm{~nm})$ and two synchronous transmission (T) and backscattering (BS) detectors. The $\mathrm{T}$ detector received the light, which crossed the sample (at $180^{\circ}$ from the incident beam). The detection head scanned the entire height of the sample cell (65-mm longitude), acquiring T each $40 \mu \mathrm{m}$ (1625 acquisitions in each scan).

\section{Counting of Viable Encapsulated and Free LGG Cells}

In order to count the encapsulated LGG viable cells both in loaded alginate-based system and in juice samples added with Coated_LGG, a treatment with phosphate buffer (PBS, pH 6.8) was applied. In details, $1 \mathrm{~g}$ of Coated_LGG or $1 \mathrm{~mL}$ of juice sample was added to $9 \mathrm{~mL}$ of PBS solution and homogenized by gentle shaking at room temperature for 10 min (until complete rupture), using an orbital shaker (IKA KS 250 basic, Labortechnik), in order to induce the alginate shell disruption and to liberate the microorganisms. The released viable LGG cells were then counted by spread plating method in MRS agar anaerobically incubated at $37{ }^{\circ} \mathrm{C}$ for $48 \mathrm{~h}$ and expressed as $\log _{10}$ colony-forming unit per gram$\mathrm{Ml}$ (CFU/g-mL). The counting of free or failed coated lactobacilli cells was carried out by serial dilution in saline solution $(0.9 \% \mathrm{w} / \mathrm{v}$ of $\mathrm{NaCl})$ and plating on MRS agar and expressed as above. 


\section{Physicochemical and Microbiological Analyses of Orange Juice Samples}

In the present study, a Sicilian $100 \%$ blood orange juice ( $\mathrm{pH} 3.05$, without any addition of sugar or preservatives) was kindly provided by the Oranfrizer Company (located in Scordia, Sicily) and used as probiotic delivery matrix. Empty CL_NP, Coated_LGG, and LGG free cells were aseptically added into $100 \mathrm{~mL}$ of orange juice. Samples were gently mixed, stored, and subjected to physicochemical and microbiological analyses. The $\mathrm{pH}$ value of samples was measured at $0,7,14$, and 35 days of storage, as described above. Total soluble solid (TSS) value, as ${ }^{\circ}$ Brix, was determined using a refractometer (Atago, RX-5000).

Samples from all treatments were analyzed in triplicate for viable count, and results expressed as mean $\log \mathrm{CFU} / \mathrm{mL}$ \pm SD. Comparison between free and encapsulated cell survivability was carried out. In addition, in order to evaluate the microbiological quality of juice for each sample, the viable count of Leuconostoc, mesophilic aerobic bacteria, psychrotrophic bacteria and yeasts/molds were detected during storage time, using Mayeux, Sandine, and Elliker (MSE), Plate Count Agar (PCA), and Sabouraud Dextrose Agar (SDA) media, incubated at 32,15 , and $25^{\circ} \mathrm{C}$, respectively.

\section{Statistical Analysis}

All experiments were carried out in triplicate, and results presented as mean \pm SD. A single-factor ANOVA was used to compare the treatments. Significant differences between the means of cell counts were determined using Tukey's HSD test. All statistical analyses were carried out using Minitab v17.3.0 (Minitab Statistical Software. Minitab Inc., USA). Results were considered statistically significant when $p<0.05$.

For the statistical analysis of CL_NP and Coated_LGG (mean size and PDI) during stability study, $t$-test was performed using Prism 6 (GraphPad Software, Inc., La Jolla, CA, USA). Significance was defined as $p<0.05$.

\section{RESULTS AND DISCUSSION}

\section{Preparation of Alginate Microcapsules}

In the present study, alginate-based particles were successfully prepared by ionotropic gelation method. The design of the formulation was performed after a preliminary investigation necessary to tune the particle preparation procedure. In particular, different factors that can affect the microencapsulation procedure, also known as "CPPs" were taken into account. The process parameters at the lowest and highest level investigated are summarized in Supplementary Table 2. The selection of specific parameter was performed based on preliminary tests and on the results reported in literature. This step was very crucial to maintain each parameter at constant value during the preparation method. Accordingly, magnetic stirring was kept at $1000 \mathrm{rpm}$; the dripping distance did not affect the procedure; thus, this parameter was not considered; particle purification was performed at $5000 \mathrm{rpm}$ at $6^{\circ} \mathrm{C}$ for $30 \mathrm{~min}$. Finally, the crosslinking time was fixed at $30 \mathrm{~min}$.
In order to minimize the experimental runs, the optimization of microencapsulation process was performed applying the BBD, based on three coded levels of the three independent variables (Table I).

The independent variables (Span ${ }^{\circledR} 80$ concentration, alginate concentration, and $\mathrm{W} / \mathrm{O}$ ratio) were set based on preliminary screening. As the concentration of surfactant $\left(X_{1}\right)$ affects the stability of the $\mathrm{W} / \mathrm{O}$ emulsion, the choice should be limited to surfactants with a low HLB value (in a range between 3 and 6). For this reason we selected Span ${ }^{\circledR} 80 \quad($ HLB $=4.3)$, and its concentration was evaluated in the range $0.1-0.5 \% \mathrm{w} / \mathrm{v}$, according to previous observations (24). Alginate concentration affected particles size, and an inverse correlation between diameter and polymer concentration $\left(X_{2}\right)$ was observed. In agreement with other reports, small particle size was obtained using $2 \% \mathrm{w} / \mathrm{v}$ alginate (25). Furthermore, since an increase in alginate concentration increases the viscosity, which could hinder syringing during the dripping, in the present study, alginate concentrations tested were set as 0.5 and $2.0 \% \mathrm{w} / \mathrm{v}$ as low and high values, respectively $(22,25)$. As already reported, additional variables, such as $\mathrm{CaCl}_{2}$ concentration and mixing speed, can affect particle properties during microencapsulation process. In the present work, these parameters were kept constant at $0.45 \mathrm{M}$ and $1000 \mathrm{rpm}$, respectively. The $\mathrm{CaCl}_{2}$ concentration affects the integrity of MCs outer membrane and should assure an optimal coverage $(22,25)$. In fact, the droplets obtained during the preparation procedure gelled on surface thanks to the ionic complex formation between alginate and calcium ions, whereas particle diameter was found to be inversely related to the mixing speed (26).

\section{Effect of Independent Variables on Particles Size and PDI}

Seventeen formulations were prepared, and their properties are shown in Table II.

Particles size and PDI were firstly correlated with the adopted independent variables through the full quadratic equations. The ANOVA analysis of the full regression models showed that only some factors (linear, quadratic, or interaction) were statistically significant; thus, statistically nonsignificant terms were removed with the exception of terms needed for hierarchy in the reduced regression model. The second-degree polynomial equations, describing the mathematical relationships between the independent and response variables obtained in the reduced regression models, are shown in Eqs. (1)-(2):

$$
\begin{aligned}
\text { Size }= & +965.02-225.84^{*} A+1.36 * B+133.15^{*} B^{2} \\
P D I= & +0.25-0.028^{*} A-0.24^{*} B+0.074^{*} C+0.11^{*} A^{*} B \\
& +0.10^{*} A^{2}+0.26^{*} B^{2}
\end{aligned}
$$

The quality of the fit of the experimental data using the reduced quadratic models was assessed based on several statistical criteria (Table III). 
Table II. Formulations Prepared According to BBD

\begin{tabular}{|c|c|c|c|c|c|}
\hline \multirow[b]{2}{*}{ Run } & \multicolumn{3}{|c|}{ Independent variables ${ }^{\mathrm{a}}$} & \multicolumn{2}{|c|}{ Dependent variables ${ }^{\mathrm{b}}$} \\
\hline & $X_{1}$ & $X_{2}$ & $X_{3}$ & $Y_{1}$ & $Y_{2}$ \\
\hline 1 & 0.5 & 1.25 & $1: 20$ & $657.5 \pm 129.0$ & $0.228 \pm 0.086$ \\
\hline 2 & 0.5 & 1.25 & $1: 6$ & $750.0 \pm 21.1$ & $0.375 \pm 0.323$ \\
\hline 3 & 0.3 & 0.5 & $1: 20$ & $918.0 \pm 9345$ & $0.678 \pm 0,558$ \\
\hline 4 & 0.1 & 2 & $1: 10$ & $1372.0 \pm 163.7$ & $0.194 \pm 0.143$ \\
\hline 5 & 0.3 & 2 & $1: 6$ & $1057.0 \pm 137.8$ & $0.436 \pm 0.342$ \\
\hline 6 & 0.3 & 1.25 & $1: 10$ & $913.8 \pm 20.6$ & $0.287 \pm 0.237$ \\
\hline 7 & 0.3 & 0.5 & $1: 6$ & $986.0 \pm 607.3$ & $0.696 \pm 0.275$ \\
\hline 8 & 0.1 & 1.25 & $1: 20$ & $1317.0 \pm 124.5$ & $0.699 \pm 0.254$ \\
\hline 9 & 0.3 & 1.25 & $1: 10$ & $924.0 \pm 260.2$ & $0.273 \pm 0.142$ \\
\hline 10 & 0.5 & 0.5 & $1: 10$ & $903.5 \pm 98.72$ & $0.776 \pm 0.168$ \\
\hline 11 & 0.1 & 1.25 & $1: 6$ & $1649.1 \pm 109.9$ & $0.520 \pm 0.425$ \\
\hline 12 & 0.3 & 1.25 & $1: 10$ & $920.0 \pm 1124$ & $0.232 \pm 0.118$ \\
\hline 13 & 0.5 & 2 & $1: 10$ & $644.5 \pm 37.3$ & $0.410 \pm 0.218$ \\
\hline 14 & 0.1 & 0.5 & $1: 10$ & $1925 \pm 906.5$ & 1 \\
\hline 15 & 0.3 & 1.25 & $1: 10$ & $978.2 \pm 222.2$ & $0.257 \pm 0.164$ \\
\hline 16 & 0.3 & 1.25 & $1: 10$ & $976.0 \pm 290.1$ & $0.149 \pm 0.107$ \\
\hline 17 & 0.3 & 2 & $1: 20$ & $709.0 \pm 21.83$ & $0.527 \pm 0.112$ \\
\hline
\end{tabular}

${ }^{a}$ Independent variables: $X_{1}=\left[\right.$ Span 80]; $X_{2}=$ [alginate]; $X_{3}=$ water:oil ${ }^{b}$ Dependent variables: $Y_{1}=$ size $(n m) \pm S D ; Y_{2}=P D I \pm S D$

As reported in Table III, the $F$-value, the $p$-value, and the $R^{2}$ revealed that the chosen quadratic models were significant, demonstrating that the quadratic model was adequate and satisfactorily explained the data for both size and PDI responses. The value of the model's adequate precision was much higher than the critical value of 4 (11.201 for $Y_{1}$ and 16.081 for $Y_{2}$ respectively), showing that the model was adequate for predicting particle size and PDI in the applied experimental domain.

The estimated coefficients (Table III) represented the contribution of each individual variable on the response (27), with the positive and negative signs indicating a synergistic or a negative relationship between variables (28).
In the case of particle size, $A$ and $B^{2}$ were the most significant model terms. During stepwise regression procedure, insignificant terms were removed from the final quadratic model equation, with the exception of the linear coefficient of $B$, which was kept to maintain the model's hierarchy. The significance of the squared term determines whether there is a quadratic effect. In fact, in our case, $B$ is a significant term but its influence on $Y_{1}$ can be represented as a curvilinear relationship.

As reported in Fig. 1 (a, b), the significant quadratic term $\left(B^{2}\right)$ indicates that the response decreases in the middle of the design space (valley in the surface) compared to the corners of the design space.

The coefficient estimated for $A$ was negative showing that along with the increase of the surfactant concentration, the mean particle size decreased (29). By reducing the surface tension, smaller droplets were formed; during the nucleation phase, a faster removal of particles from the emulsion occurred, facilitating the formation of particles with reduced dimensions $(18,30)$. Indeed, during the preparation, surfactant covers the developed particles preventing their further growth; furthermore, their surface energy decreased preventing the agglomeration phenomena. The coefficient estimated for $B^{2}$ indicated that as the polymer concentration increased, particle diameter gradually increased, as previously reported $(25,31)$.

Furthermore, as shown in Supplementary Figure 1, a good correlation between the actual and predicted values was observed, confirming a good fitting and that the BBD model can be effectively applied for optimization.

Regarding PDI response, $B, C, \mathrm{AB}, A^{2}$, and $B^{2}$ were found to be significant model terms (Fig. 2). All factors affected this response, as individual term and/or in combination. When an interaction term is found to be significant, the correspective linear terms are critical to the model because they are the parent terms to the interaction. The interaction coefficient is basically a correction to the individual parent term coefficient when the second parent is set at its different levels. The interaction that mainly affected the PDI response $\left(Y_{2}\right)$ was $\mathrm{AB}$, which referred to the interaction between Span 80 and alginate concentration.

Table III. Analysis of Variance Results

\begin{tabular}{|c|c|c|c|c|c|c|}
\hline \multirow[b]{2}{*}{ Polinomyal term } & \multicolumn{3}{|l|}{ Particle size } & \multicolumn{3}{|l|}{ Polydispersity } \\
\hline & Coeff. estimate & & $P$ value & Coeff. estimate & & $P$ value \\
\hline Model & & Quadratic $^{\mathrm{a}}$ & 0.0002 & & Quadratic $^{a}$ & $<0.0001$ \\
\hline$A$ & -225.84 & & $<0.0001$ & -0.028 & & 0.3222 \\
\hline$B$ & 1.36 & & 0.9722 & -0.24 & & $<0.0001$ \\
\hline$C$ & & & & 0.074 & & 0.0199 \\
\hline $\mathrm{AB}$ & & & & 0.11 & & 0.0160 \\
\hline \multicolumn{7}{|l|}{$\mathrm{AC}$} \\
\hline \multicolumn{7}{|l|}{ BC } \\
\hline$A^{2}$ & & & & 0.10 & & 0.0206 \\
\hline$B^{2}$ & 133.15 & & 0.0247 & 0.26 & & $<0.0001$ \\
\hline \multicolumn{7}{|l|}{$C^{2}$} \\
\hline$R^{2}$ & & 0.7615 & & & 0.9380 & \\
\hline$F$ value & & 13.83 & & & 25.19 & \\
\hline
\end{tabular}

${ }^{a}$ Reduced quadratic model 
a

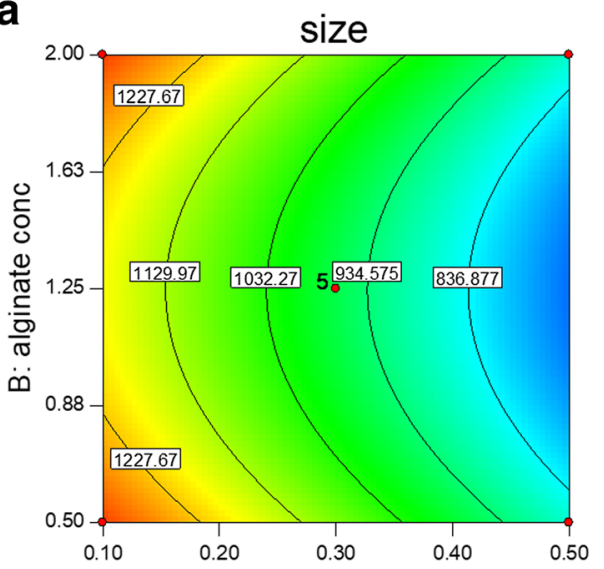

A: span conc b

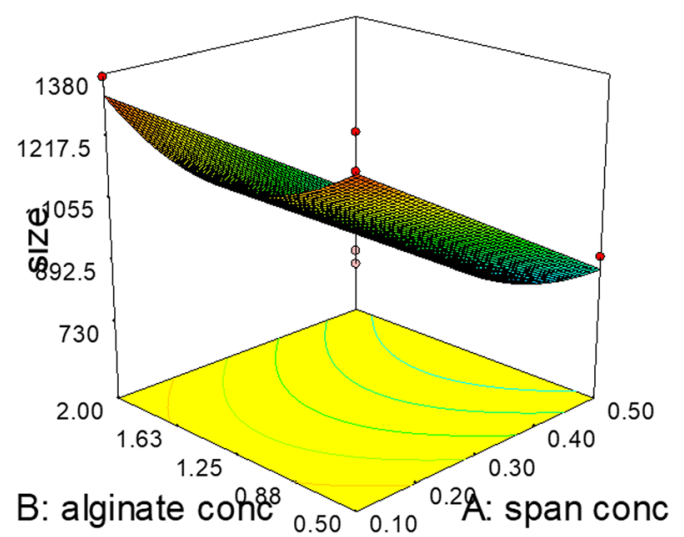

Fig. 1. Contour plot (a) and $3 \mathrm{D}$ surface $(\mathbf{b})$ of the effect of alginate $(\mathrm{mg} / \mathrm{ml})$ versus Span 80 concentration $(\%)$ on the particles size

The interaction contour and 3D surface plots (alginate concentration versus Span concentration) that resulted from the developed reduced quadratic model (Fig. 2a, b) depicted the increase in the PDI with a reduction in both span and alginate concentration, so that a maximum PDI value of 1 is reached at the minimum values of these two factors in the selected experimental domain.

Consequently, high concentrations of surfactant and polymer should be used to obtain homogeneous particles. The surfactant played an important role in stabilizing the particles in suspension. Furthermore, the stability was strictly related to low PDI values. High polydispersity may cause serious drawbacks such as unpredictable behavior (32). Particle surface coverage increases higher surfactant concentration, which may also guarantee the steric resistance of the shell. Conversely, an insufficient surfactant concentration could reduce the system's stability (33).

\section{Optimized Alginate System}

Once the factors and variables exerting a significant impact on the dependent variables of alginate-based particles were assessed, the formulation candidate to load probiotic cells was optimized. For the numerical optimization, the desired goals for each response (none, minimize, maximize, target, or range) were applied (Supplementary Table I). As showed in Supplementary Table I, the candidate formulation target parameters were particle size near $1000 \mathrm{~nm}$ that allowed coating the bacteria cells as a layer. At the same time, this particle diameter maintains the sensorial traits of juice. Then, we set to minimize the PDI to obtain a homogeneous suspension.

In order to determine the best combination of responses, the objective function involved the use of a geometric mean for the search of the greatest overall desirability for responses and/or factors. Desirability values equal to 1 indicated that all goals were satisfied. Differently, values equal to 0 indicated that one or more responses fall outside the acceptable limits.

The formulation proposed with the highest desirability (0.973) was selected and experimentally validated. Its composition was $X_{1} 0.42 \% \mathrm{w} / \mathrm{v}, X_{2} 2 \% \mathrm{w} / \mathrm{v}$, and $X_{3} 1: 20 \mathrm{v} / \mathrm{v}$.
The predicted and observed values were compared, and the error percentage was calculated for each response, as shown in Table IV. All percentage errors were considered satisfactory $(<10 \%)$. Overall, results showed a good correlation between the observed and predicted values, which confirmed the reliability of the model. The optimized particles showed negative surface charge $(-48.6 \pm 1.10 \mathrm{mV})$ due to the presence of alginate.

TEM images of empty optimized formulation are shown in Fig. 3 (a, b). As suggested by PDI values, the images revealed that the optimized CL_NP consists of a cluster of nanoparticles with spherical shape and smooth surface. Moreover, the CL_NP displays a continuous wall free of cracks and surface indentation, essential to provide good protection to the core and prevent an uncontrolled cargo release (34). These observations confirmed that the obtained formulation consisted of capsules, as demonstrated by the different color intensity that well differentiates the shell in the outer part of the particle from the core, located in the innermost zone with a more marked color.

\section{Lacticaseibacillus rhamnosus GG Cell-Loaded Alginate Particles}

The optimized formulation was selected for probiotic loading, and a comparison was made between the empty and the loaded systems. When probiotic cells were encapsulated (Coated_LGG), the average size of the systems slightly increased (from $1047 \mathrm{~nm}$ to $1165 \mathrm{~nm}$ ), and TEM analysis revealed that the system modified its structure from a spherical CL_NP (Fig. 3b) as cluster (Fig. 3c) to a structure elongated and with elliptical shape (Fig. 3c, d).

The PDI of loaded formulation decreased from 0.266 to 0.181 , indicating a higher particle homogeneity compared to empty CL_NP. The ZP remained negative with values equal to $-36 \pm 0.557$.

In general, the probiotic microencapsulation strategy may allow to obtain particles that consist of one or several cells. When several cells are enclosed by the capsule, the interstitial liquid from solution fills the free spaces of the "multicells microcapsule". Our results suggest the presence of 
a

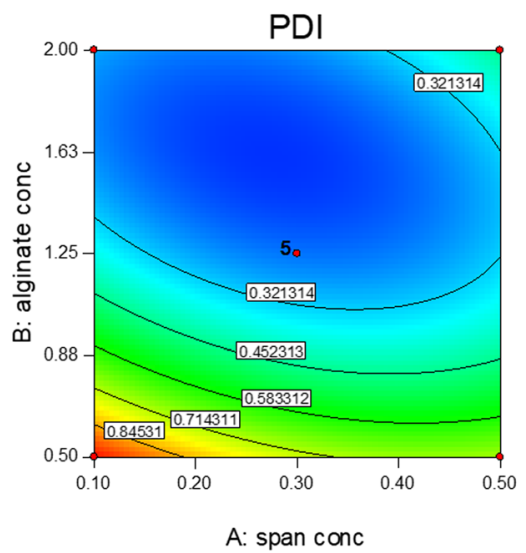

C

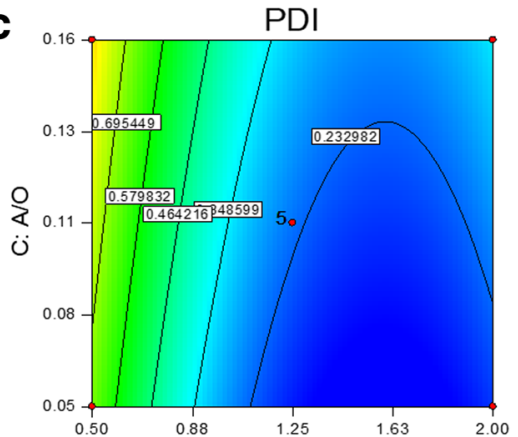

$\mathrm{B}$ : alginate conc

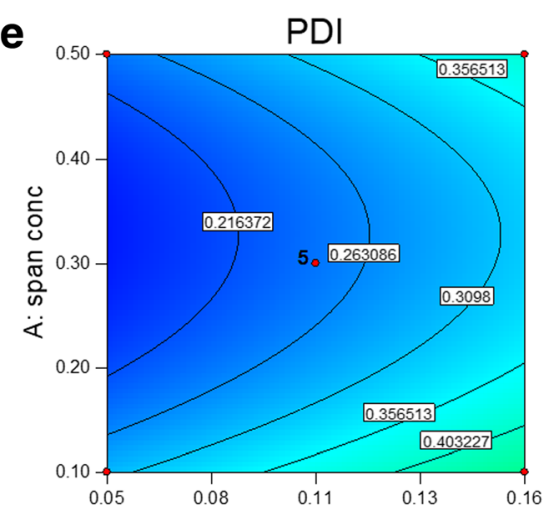

b

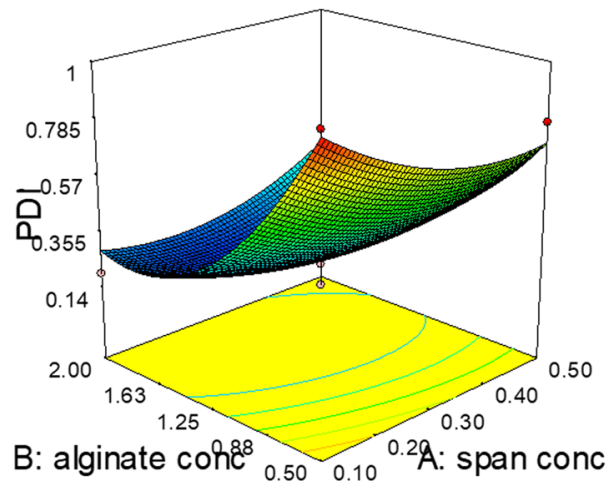

d

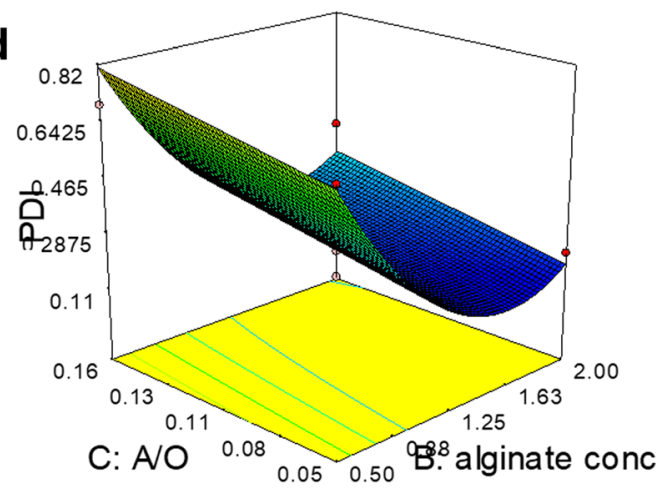

f

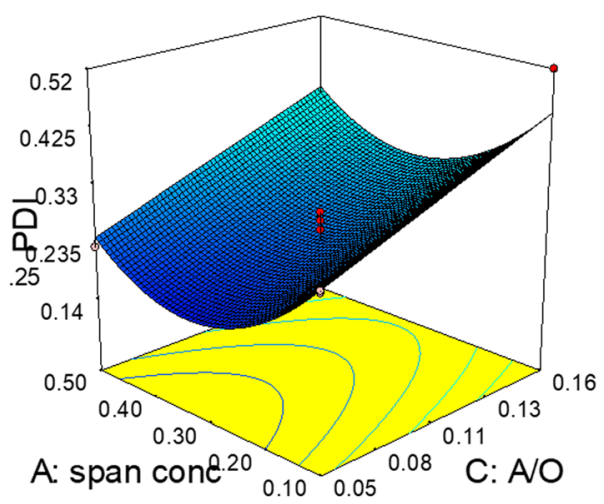

Fig. 2. Contour plot (a) and 3D surface (b) of the effect of alginate $(\mathrm{mg} / \mathrm{ml})$ versus Span 80 concentration (\%); contour plot (c) and 3D surface (d) of the effect of alginate concentration $(\mathrm{mg} / \mathrm{ml})$ versus $\mathrm{A} / \mathrm{O}$ ratio $(\mathrm{v} / \mathrm{v})$; contour plot $(\mathbf{e})$ and 3D surface (f) of the effect of Span80 concentration (\%) versus A/O ratio (v/v) on particles PDI

Table IV. Results of Dependent Variables Obtained from the Optimized Formulation: Predicted, Observed Values, and Error Percentage

\begin{tabular}{llll}
\hline & Predicted value & Observed value $^{\mathrm{a}}$ & Error $^{\mathrm{b}}$ \\
\hline$Y_{1}(\mathrm{~nm})$ & 994.56 & $1047 \pm 18.07$ & 5.27 \\
$Y_{2}$ & 0.251 & $0.266 \pm 0.027$ & 5.97 \\
\hline
\end{tabular}

${ }^{a}$ Particle mean size $\pm S D ; P D I \pm S D$

${ }^{b}$ Absolute predicted error $=\mid($ Obs.value-Pred.value $) /$ Pred.value $\mid * 100$ a single-cell encapsulation with the bacterial cell forming the core of the capsule, surrounded by the polymeric shell. This hypothesis is supported by previous studies by Mortazavian et al., who described the possibility to add an additional second layer to the polymeric capsule, also known as shell, coat, or support layer (35). TEM images of loaded formulation (Fig. 3c, d) highlighted the typical cell morphology of LGG and surrounded by a layer of polymer; in fact, the images did not show other structure that may hypothesize that alginate formed separate nanosystem. During encapsulation, the polymer "adapts" itself to the present cells stratifying along their surface as a protective coating. In this 

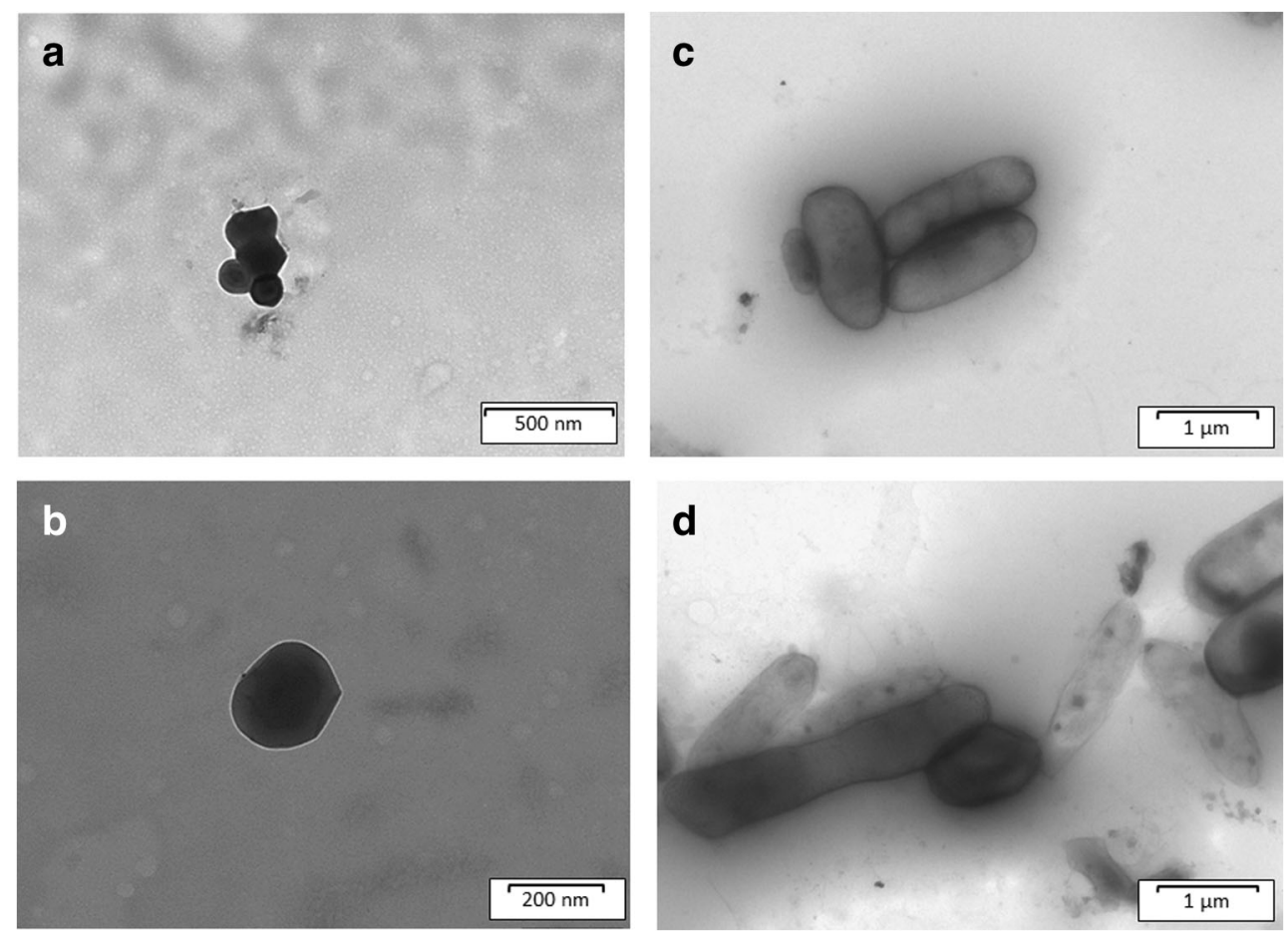

Fig. 3. TEM images of optimized empty cluster of nanoparticles (CL_NP) (a, b); TEM images of coated Lacticaseibacillus rhamnosus GG (Coated_LGG) (c, d)

way, we successfully obtained a microcaspular system containing probiotic cell, to preserve the juice properties that will not be affected by the presence of macroscopic visible particles.

\section{Stability Evaluation}

Stability tests were performed during storage of the CL_NP and Coated_LGG formulations in orange juice for 1 week. Samples were kept at 5 and $25^{\circ} \mathrm{C}$ and subjected to PCS and $\mathrm{pH}$ evaluation, while Turbiscan $\AA$ analysis was performed only at $25^{\circ} \mathrm{C}$.

As reported in Fig. 4a, both empty CL_NP and Coated_LGG showed high stability at $5^{\circ} \mathrm{C}$; no variation in particle diameter was highlighted, with reduction of PDI values in both formulations. Both samples stored at room temperature showed a reduction of particle diameter and an increase of PDI values (Fig. 4b).

XParticle ZP was affected by the matrix, as revealed by the shift toward neutral values, at 0 time for CL_NP (Fig. $4 c, d)$. The difference in ZP values observed in fruit juice and aqueous suspension is due to the particles' environment, as the $\mathrm{ZP}$ is defined as difference of potential between the dispersion medium and the stationary layer of fluid attached to the dispersed particles. One of the most important factors that affects $\mathrm{ZP}$ is the $\mathrm{pH}$ of the medium. Even in the case of Coated_LGG, a decrease in the $\mathrm{ZP}$ values was observed, which was found to be higher at $25^{\circ} \mathrm{C}$. The $\mathrm{pH}$ of CL_NP and Coated_LGG was stable along the storage time, as reported in Fig. 4e, f. After 7 days, a reduction of $\mathrm{ZP}$ with negative values $\sim-6 \mathrm{mV}$ was observed at both temperatures.

In addition, CL_NP and Coated_LGG were furtherly analyzed through Turbiscan $\AA$, to obtain information on physical stability of colloidal suspensions in terms of particle migration or aggregation $(36,37)$. Turbiscan ${ }^{\circledR}$ Stability Index (TSI) considers all phenomena occurring inside the glass cell at a specific sampling point (37). As shown in the destabilization kinetics, reported in Fig. 5, both CL_NP and Coated_LGG showed higher values compared to fruit juice alone at $25^{\circ} \mathrm{C}$, and variation in the TSI was observed after 7 days of storage. The alginate system accelerated the sedimentation of the pulp presented in fruit juice. In order to further investigate the instability phenomena, we also evaluated the BS profiles of the formulations (Fig. 6).

Insignificant instability phenomena $(\Delta \mathrm{BS}>10 \%)$ was registered for both CL_NP and Coated_LGG (Fig. 6 b and c, respectively) compared to the fruit juice (Fig. 6a), due to reversible particle migration at both the bottom and the top of the cuvette. $\Delta \mathrm{BS}$ along the glass cell provides information related to the sample homogeneity, confirming the PDI variation observed through PCS. Furthermore, a linear profile for CL_NP and Coated_LGG in the middle of the glass cell was observed, clearly revealing the absence of particle size increase related to aggregation phenomena.

\section{Counting of Encapsulated LGG and Microbiological Analyses of Juice Samples}

The initial bacterial population subjected to encapsulation was around $9.11 \log _{10} \mathrm{CFU} / \mathrm{mL}$. High cell entrapping (8.07 $\log _{10}$ CFU/g Coated_LGG) was achieved in Coated_LGG, with no significant loss of viability and with about $87 \%$ of successfully entrapped cells (data not shown).

The viability of microencapsulated cells was monitored into orange juice during refrigerated storage and compared to viability of free cells added and naturally present in juice, including failed encapsulated cells. Juice samples with no added probiotic bacteria were also analyzed under the same conditions as control. The microbial population dynamics detected in orange juice samples during 35 days of storage at 
a

$5^{\circ} \mathrm{C}$

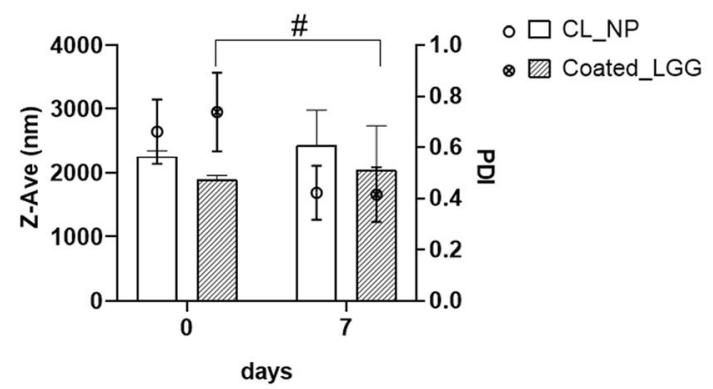

C

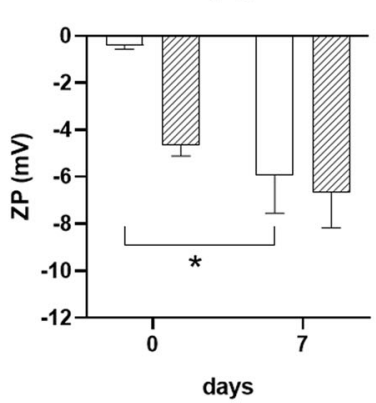

e

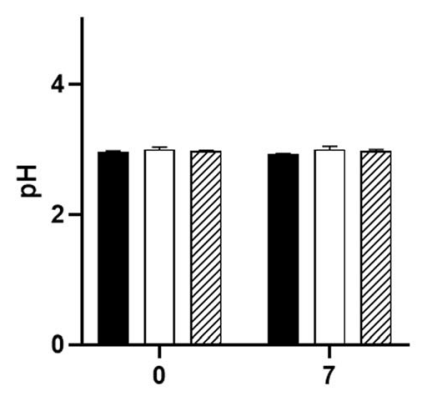

days

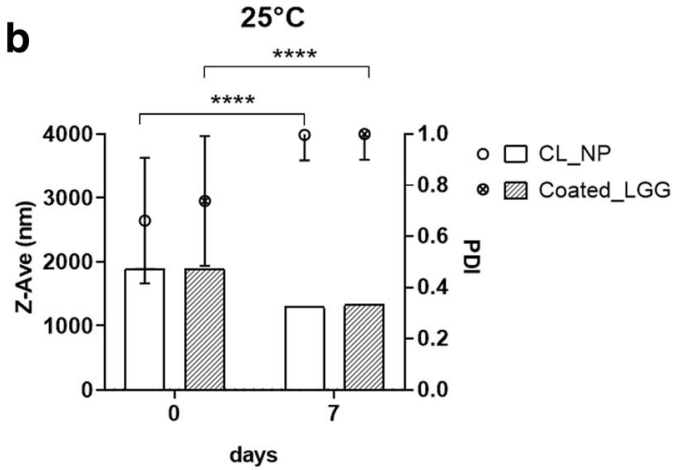

d

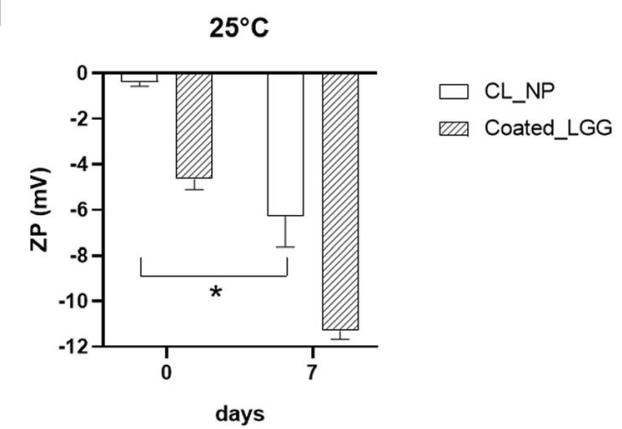

f $25^{\circ} \mathrm{C}$

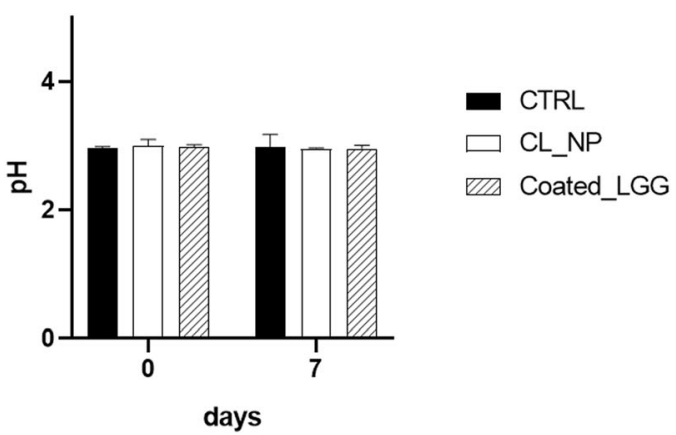

Fig. 4. Stability studies: mean size, PDI (a), $\mathrm{ZP}(\mathbf{c})$, and $\mathrm{pH}(\mathbf{d})$ of the samples stored at $5^{\circ} \mathrm{C}$ and mean size, PDI (b), $\mathrm{ZP}(\mathbf{d}), \mathrm{pH}(\mathbf{f})$ of the samples stored at $25^{\circ} \mathrm{C}$. The asterisk symbol denotes statistical significance difference for size and zeta potential. The number sign symbol denotes statistical significance difference for PDI. Significance was defined as $* * * * p<0.0001$

\section{Destabilisation Kinetics (Global)}

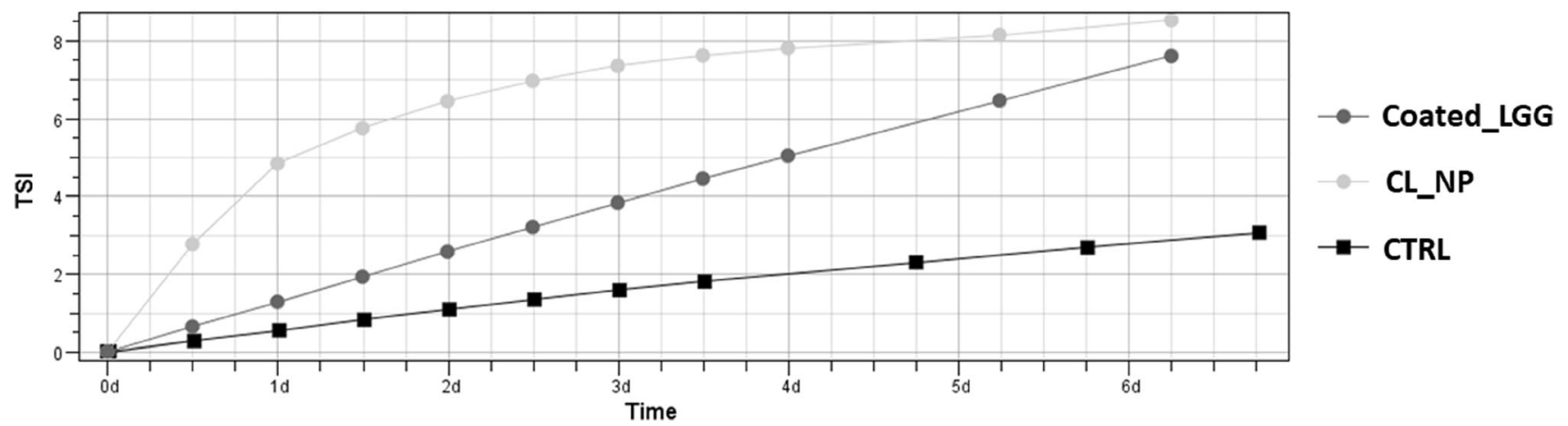

Fig. 5. Destabilization kinetics expressed by Turbiscan Stability Index (TSI) of orange fruit juice (CTRL), empty cluster of nanoparticles (CL_NP), and coated Lacticaseibacillus rhamnosus GG (Coated_LGG) stored 7 days at $25^{\circ} \mathrm{C}$ 
a
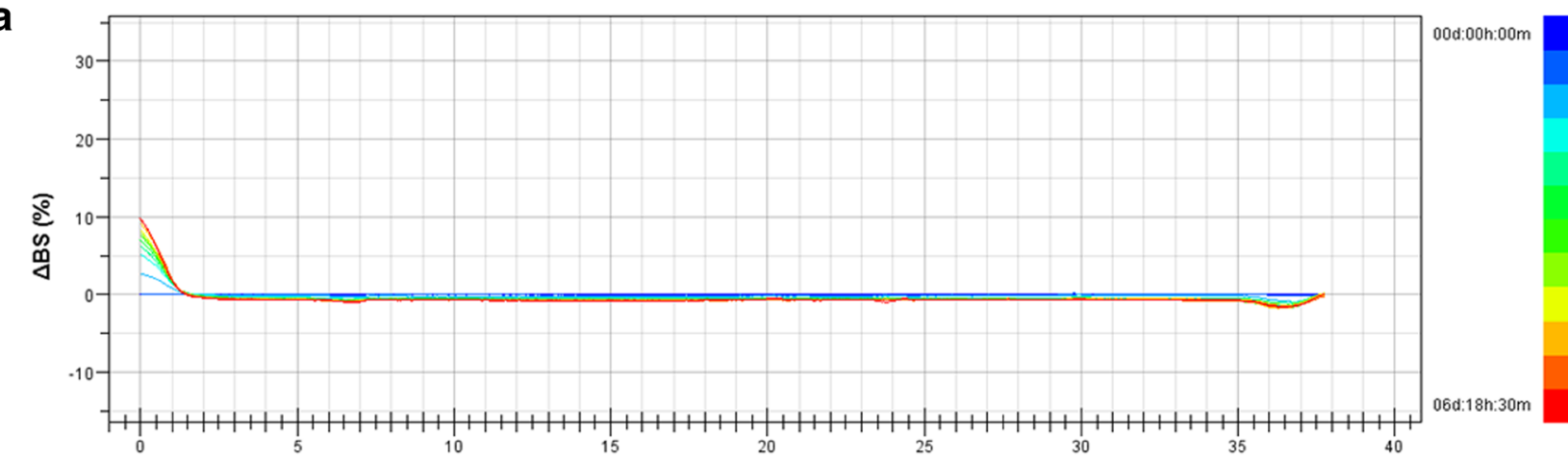

b

Height (mm)

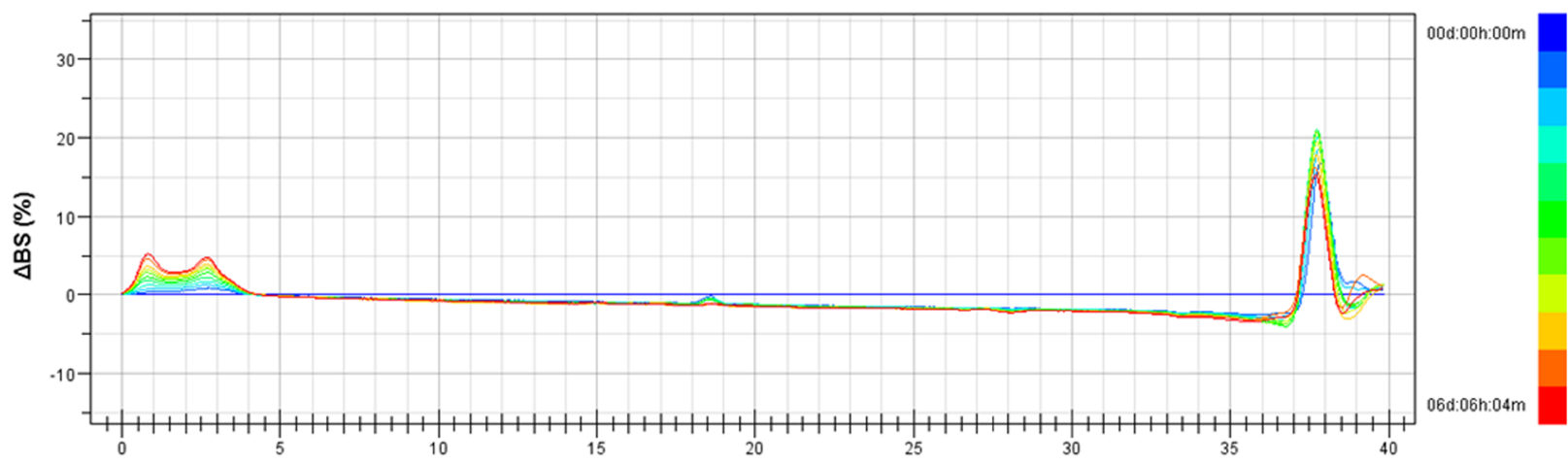

C

Height (mm)

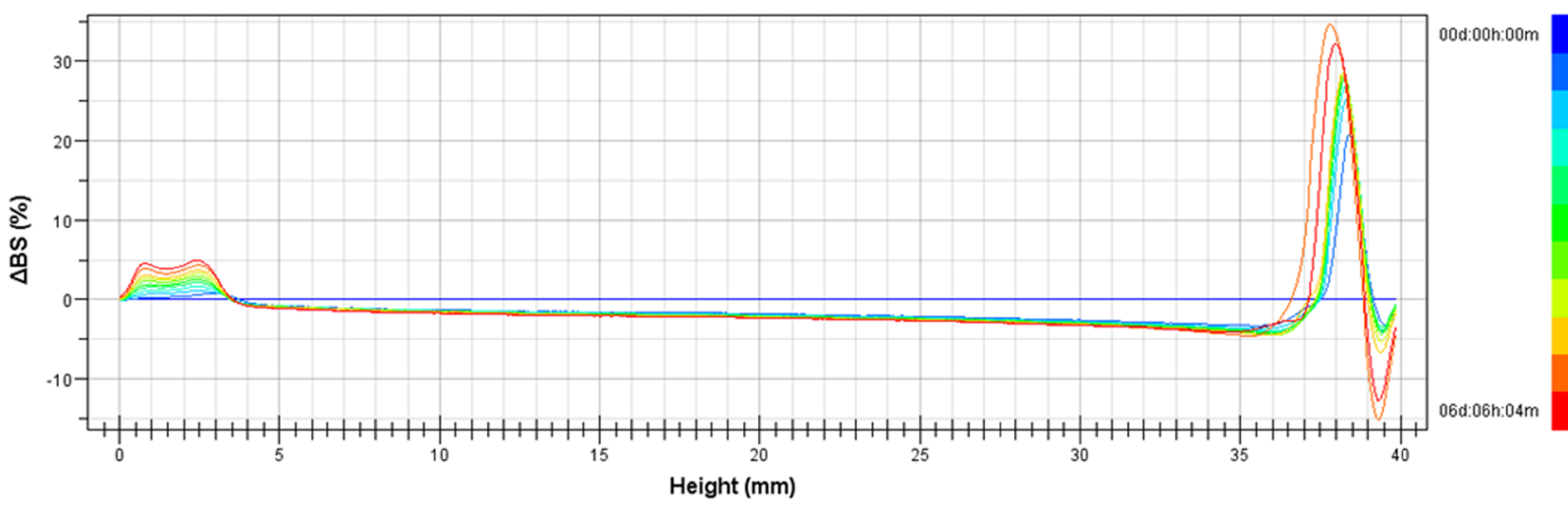

Fig. 6. Backscattering profiles ( $\triangle \mathrm{BS})$ of orange fruit juice (CTRL) (a), empty cluster of nanoparticles (CL_NP) (b), and coated Lacticaseibacillus rhamnosus GG (Coated_LGG) (c) stored in Turbiscan ${ }^{\circledR}$ at $25^{\circ} \mathrm{C}$ for 1 week

$5^{\circ} \mathrm{C}$ are shown in Table $\mathrm{V}$, while the survival of $\mathrm{LGG}$, in both experimental samples (with Coated_LGG or free LGG) reported as differences $(\Delta \log )$ between completely coated cells or free added cells and lactobacilli naturally present (including not coated LGG), is reported in Fig. 7.

The densities of lactobacilli in juice samples, added with Coated_LGG, ranged between about 9.0, at initial time, and $8.3 \log \mathrm{CFU} / \mathrm{mL}$ after 35 days of refrigerated storage (Table V). During storage, significant differences in lactobacilli densities were observed only at the 14th and 35 th days of storage, highlighting a slight decrease, reaching an average value of about 8.6 and $8.3 \log \mathrm{CFU} / \mathrm{mL}$, respectively. Our results confirmed previous reports on the effects of microencapsulation on maintenance cell viability into fruit juice for 2 weeks (38). This finding has been ascribed to a more favorable anaerobic microenvironment for bacteria or to a physical barrier against the acidic conditions of fruit juices (39). It is interesting to highlight that the cell density observed after 35 days was almost equivalent to the initial value of added LGG cells, thus revealing that the microcapsules remained intact in the juice and confirming the ability of sodium alginate to protect cells. Juice added with free LGG showed a lower survival rate (Table V), with a constant lactobacillus decrease, from the initial $7.93 \mathrm{CFU} / \mathrm{mL}$ to $5.58 \mathrm{CFU} / \mathrm{mL}$ at the 35 th day of storage. Although several studies reported a good stability of LGG strain in orange juice (40), many other reports highlighted a considerable variability mostly referred to intrinsic parameters of juice (namely microbial loads) or processing and storage temperature $(40,41)$.

Interestingly, our results demonstrated only an insignificant decrease in viability after 7 days of storage; this 


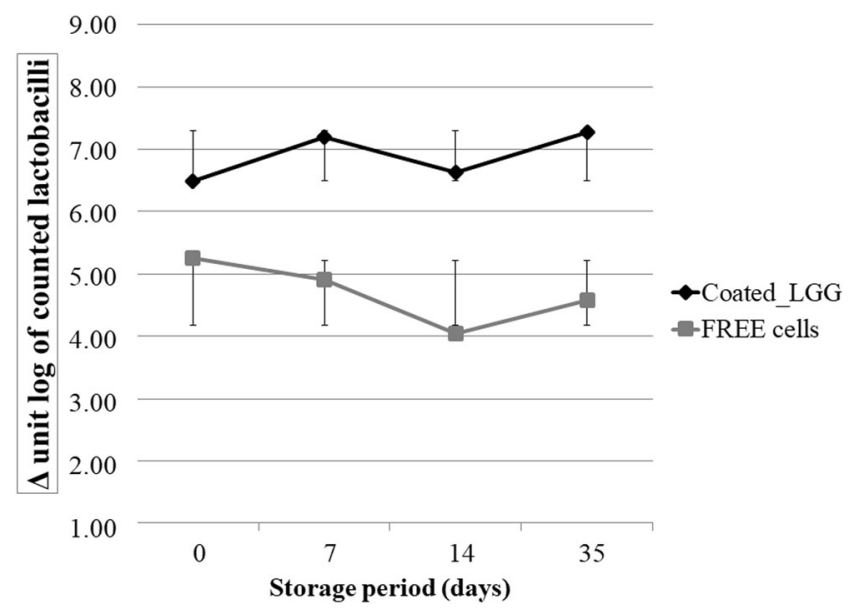

Fig. 7. Viability of LGG cells, in free and microencapsulated forms, during refrigerated $\left(5^{\circ} \mathrm{C}\right)$ storage (days) in blood orange juices. Data are expressed as differences between lactobacilli densities detected in experimental and control juice samples (uninoculated juice)

result was in contrast to literature findings that showed how the viability of free probiotic cultures in fruit juices is difficult to maintain for low $\mathrm{pH}$, high concentration of dissolved oxygen, and low concentrations of free amino acids and peptides (3).

Additionally, in order to obtain a microbiological picture of juice with and without alginate microcapsules, further microbiological analyses were performed. Overall, the microbiological results (Table $\mathrm{V}$ ) confirmed that all tested orange juices were in compliance with the limits dictated by the CE Regulation 2073/05 (41). In control samples (CTRL), Leuconostoc spp. counts showed a slight decrease after 7 days of storage to remain almost constant up to end of storage (Table V). Mesophilic counts showed a swinging trend with an initial slight decrease, an increase up to the 14th day of storage, and further decrease up to the 35 th day of storage when the value of $1.31 \log \mathrm{CFU} / \mathrm{mL}$ was reached. An initial reduction (1.07 log unit) was observed for mold/yeast densities, which reached the value of $1.30 \log \mathrm{CFU} / \mathrm{mL}$ after 35 days of storage (Table V). Psychotropic bacteria, not detectable at initial time, reached the final values of 1.50 $\log \mathrm{CFU} / \mathrm{mL}$. Zooming on inoculated juices Leuconostoc showed a stable density, of about $2 \log \mathrm{CFU} / \mathrm{mL}$ until the end of the storage, although microbiological count was somehow higher for the Coated_LGG juices compared to the CTRL juice. Regarding mesophilic bacteria, an increase of about 1 log unit was observed after 7 days, followed by a decrease after 14 and 35 days (Table V). Fluctuations in the counts of molds and yeasts were registered with a peak density recorded (about 5.00 log $\mathrm{CFU} / \mathrm{mL}$ ) after 14 days and a further decrease (4.80 log $\mathrm{CFU} / \mathrm{mL}$ ) at the end of storage. The psychrotrophic bacteria reached a value of $3.10 \log \mathrm{CFU} / \mathrm{mL}$ after 14 days of storage and a subsequent decrease (1.51 log CFU/ $\mathrm{mL}$ ) after 35 days.

The addition of free LGG cells into orange juice contributed to an increase of other microbial groups. In details, a constant increase was observed for Leuconostoc spp., along the storage period, reaching the value of $8.00 \mathrm{log}$ CFU/mL after 35 days (Table V). Regarding mesophilic 
bacteria, about $2 \log$ unit increase at any sampling time was observed, reaching, after 35 days, a value of $8.00 \mathrm{log}$ CFU/ $\mathrm{mL}$, while a lower increase (1.06 log units) was detected for mold/yeast counts that reached the value of $4.68 \log \mathrm{CFU} / \mathrm{mL}$ at the end of storage (Table V). After 7 days, the psychrotrophic bacteria increased to reach the highest density (3.51 log CFU/mL) after 14 days and a final value of $1.65 \log$ CFU/mL (Table V).

Overall, the results of the present study highlighted that the microencapsulation represents a promising approach for juice preservation, to improve the stability of the final product. Although fruit juice is a suitable matrix for spoilage microbial growth and supporting the growth of molds/yeasts, heterofermentative LAB species, and above all Leuconostoc spp. (42,43), the microencapsulation strategy was found more effective for reducing the overgrowth of microorganisms, compared to the addition of free LGG. Even if the yeasts' presence may cause color loss and the formation of a sediment at the bottom, with consequent turbidity, flocculation, pellicles, and clumping, in our study, no visual differences among tested juice samples were revealed (Supplementary Figure 2).

\section{pH and Total Soluble Solid $\left({ }^{\circ}\right.$ Brix $)$}

The initial $\mathrm{pH}$ values of blood orange juice samples were between 2.75 and 3.45. Overall, the $\mathrm{pH}$ value remained almost constant in treated and non-treated juices at any sampling time, in agreement with previous studies. Champagne and Gardner (44) studied the stability at $4{ }^{\circ} \mathrm{C}$ of nine probiotic lactobacilli in a drink, composed of 10 fruits and dairy ingredients, observing that the $\mathrm{pH}$ of samples remained unchanged after 28 days of storage due to the weak metabolic activity of the lactobacilli at $4^{\circ} \mathrm{C}$. Similarly, the same authors found a variation in $\mathrm{pH}$ between 3.63 and 3.90, when L. rhamnosus R0011 was inoculated (at $4.5 \times 10^{9}$ CFU/250 mL) into an apple-pear-raspberry juice blend (45). The inoculated juices showed $\mathrm{pH}$ values less than 0.1 unit lower than the non-inoculated juices. In the same way, the total soluble solids did not significantly change in any tested samples during storage.

\section{CONCLUSION}

This study was aimed at the preparation of alginatebased system for probiotic delivery into juices. The BBD revealed that polymer and surfactant concentrations are the main factors determining particle properties. The optimized particles were prepared using 2\% alginate and $0.4 \%$ Span 80 which led to particles with a diameter $\sim 1000 \mathrm{~nm}$. The experimental data of the optimized formulation were in accordance with the predicted ones, suggesting that the experimental design was a valid approach for the investigation and optimization of new formulations. Additionally, the morphological analysis revealed the capsular structure of the unloaded systems, showing a cluster organization in aqueous media. The optimized formulation loaded with the probiotic (Coated_LGG) was found to be homogeneous with a slight increase in mean size in comparison to unloaded CL_NP.
Indeed, the elongated elliptical shape revealed that the coating process is one to one for bacterial cells.

Microbiological evaluation revealed that the encapsulation assured the survival of Coated_LGG, in a $100 \%$ orange juice for 28 days. Moreover, results indicated that the microencapsulated bacteria preserved the macroscopic properties and the microbiological characteristic of orange juice and assured the required amount of probiotic live cells to obtain a temporary colonization of the intestine. Further studies are required to test the survival of microencapsulated strain through the gastrointestinal tract in vitro.

\section{SUPPLEMENTARY INFORMATION}

The online version contains supplementary material available at https://doi.org/10.1208/s12249-021-01996-x.

\section{Abbreviations}

\section{ACKNOWLEDGEMENTS}

We thank the Oranfrizer Company (Scordia, Sicily) for kindly supplying the orange juice samples.

\section{FUNDING}

Open access funding provided by Università degli Studi di Catania within the CRUI-CARE Agreement. This work was partially supported by funding from the Ministero dell'Istruzione, dell'Università e della Ricerca, University of Catania (Italy), under the Piano della Ricerca PIA.CE.RI. 2020-2022 Linea 2-Progetto intradipartimentale RiDARE. Grant number: UPB 5A722192158 and from project PON I\&C-Asse I, Azione 1.1.3, C3 Carbon Capture \& Conversion, project number F/090015/01/X36 - CUP: B28I17000540008- COR: 588727.

\section{DECLARATIONS}

Conflict of Interest The authors declare no competing interests.

\section{REFERENCES}

1. Afzaal M, Saeed F, Arshad MU, Nadeem MT, Saeed M, Tufail T. The effect of encapsulation on the stability of probiotic bacteria in ice cream and simulated gastrointestinal conditions. Probiotics Antimicrob Proteins. 2019;11(4):1348-54.

2. Hill C, Guarner F, Reid G, Gibson GR, Merenstein DJ, Pot B, et al. Expert consensus document: the International Scientific Association for Probiotics and Prebiotics consensus statement on the scope and appropriate use of the term probiotic. Nat Rev Gastroenterol Hepatol. 2014;11(8):506-14.

3. Olivares A, Soto C, Caballero E, Altamirano C. Survival of microencapsulated Lactobacillus casei (prepared by vibration technology) in fruit juice during cold storage. Electron J Biotechnol. 2019;42:42-8. https://doi.org/10.1016/ j.ejbt.2019.10.002. 
4. Randazzo CL, Pitino I, Licciardello F, Muratore G, Caggia C. Survival of Lactobacillus rhamnosus probiotic strains in peach jam during storage at different temperatures. Food Sci Technol. 2013;33(4):652-9.

5. Randazzo CL, Todaro A, Pino A, Pitino I, Corona O, Mazzaglia A, et al. Giarraffa and Grossa di Spagna naturally fermented table olives: effect of starter and probiotic cultures on chemical, microbiological and sensory traits. Food Res Int. 2014;62:115464. https://doi.org/10.1016/j.foodres.2014.05.056.

6. Burgain J, Gaiani C, Linder M, Scher J. Encapsulation of probiotic living cells: from laboratory scale to industrial applications. J Food Eng. 2011;104(4):467-83.

7. Govender M, Choonara YE, Kumar P, Du Toit LC, Van Vuuren S, Pillay V. A review of the advancements in probiotic delivery: conventional vs. non-conventional formulations for intestinal flora supplementation. AAPS PharmSciTech. 2014;15(1):29-43.

8. da Costa GM, de Carvalho Silva JV, Mingotti JD, Barão CE, Klososki SJ, Pimentel TC. Effect of ascorbic acid or oligofructose supplementation on L. paracasei viability, physicochemical characteristics and acceptance of probiotic orange juice. LWT Food Sci Technol. 2017;75:195-201.

9. Pimentel TC, Madrona GS, Garcia S, Prudencio SH. Probiotic viability, physicochemical characteristics and acceptability during refrigerated storage of clarified apple juice supplemented with Lactobacillus paracasei ssp. paracasei and oligofructose in different package type. LWT Food Sci Technol. 2015;63(1):415-22.

10. Porto MRA, Okina VS, Pimentel TC, Garcia S, Prudencio SH. Beet and orange mixed juices added with Lactobacillus acidophilus. Nutr Food Sci. 2018;48(1):76-87.

11. E Silva JPS, Sousa SC, Costa P, Cerdeira E, Amaral MH, Lobo JS, et al. Development of probiotic tablets using microparticles: viability studies and stability studies. AAPS PharmSciTech. 2013;14(1):121-7.

12. Lauro, M.R., Musumeci, T., Sansone, F., Puglisi, G., Pignatello R. Lauro. In: Madhu Gupta, Durgesh Nandini Chauhan, Vikas Sharma NSC, editor. Novel drug delivery systems for phytoconstituents. CRC Press; 2019. p. 261-282.

13. Ministry of Health. Guidelines on probiotics and prebiotics Revision March 2008:1-4.

14. Shaharuddin S, Muhamad II. Microencapsulation of alginateimmobilized bagasse with Lactobacillus rhamnosus NRRL 442: Enhancement of survivability and themotolerance. Carbohydr Polym. 2015;119:173-81.

15. Craparo EF, Drago SE, Giammona G, Cavallaro G. Production of polymeric micro- and nanostructures with tunable properties as pharmaceutical delivery systems. Polymer . 2020;200:122596. https://doi.org/10.1016/j.polymer.2020.122596

16. Goh CH, Heng PWS, Chan LW. Alginates as a useful natural polymer for microencapsulation and therapeutic applications. Carbohydr Polym. 2012;88(1):1-12.

17. Patel MA, AbouGhaly MHH, Schryer-Praga JV, Chadwick K. The effect of ionotropic gelation residence time on alginate cross-linking and properties. Carbohydr Polym. 2017;155:36271.

18. Bonaccorso A, Gigliobianco MR, Pellitteri R, Santonocito D, Carbone C, Di Martino P, et al. Optimization of curcumin nanocrystals as promising strategy for nose-to-brain delivery application. Pharmaceutics. 2020;12(5).

19. Patel YL, Sher P, Pawar AP. The effect of drug concentration and curing time on processing and properties of calcium alginate beads containing metronidazole by response surface methodology. AAPS PharmSciTech. 2006;7(4).

20. Renard A, Gómez di Marco P, Egea-Cortines M, Weiss J. Application of whole genome amplification and quantitative PCR for detection and quantification of spoilage yeasts in orange juice. Int J Food Microbiol. 2008;126(1-2):195-201.

21. Rodríguez-Dorado R, Landín M, Altai A, Russo P, Aquino RP, Del Gaudio P. A novel method for the production of core-shell microparticles by inverse gelation optimized with artificial intelligent tools. Int J Pharm. 2018;538(1-2):97-104.
22. Zheng J, Wittouck S, Salvetti E, Franz CMAP, Harris HMB, Mattarelli P, et al. A taxonomic note on the genus Lactobacillus: description of 23 novel genera, emended description of the genus Lactobacillus Beijerinck 1901, and union of Lactobacillaceae and Leuconostocaceae. Int J Syst Evol Microbiol. 2020;70(4):2782-858.

23. Segers ME, Lebeer S. Towards a better understanding of Lactobacillus rhamnosus GG - host interactions. Microb Cell Factories. 2014;13 ( S uppl 1):S 7 ht tp:// www.microbialcellfactories.com/content/13/S1/S7.

24. D'Orazio G, Di Gennaro P, Boccarusso M, Presti I, Bizzaro G, Giardina S, et al. Microencapsulation of new probiotic formulations for gastrointestinal delivery: in vitro study to assess viability and biological properties. Appl Microbiol Biotechnol. 2015;99(22):9779-89.

25. Renard D, Martins E, Poncelet D. Food hydrocolloids monodisperse core-shell alginate ( micro ) -capsules with oil core generated from droplets milli fluidic. 2017;63:447-56.

26. Martins E, Poncelet D, Renard D. A novel method of oil encapsulation in core-shell alginate microcapsules by dispersion-inverse gelation technique. React Funct Polym. 2017;114:49-57.

27. Hao J, Gao Y, Zhao J, Zhang J, Li Q, Zhao Z, et al. Preparation and optimization of resveratrol nanosuspensions by antisolvent precipitation using Box-Behnken Design. AAPS PharmSciTech. 2014;16(1):118-28.

28. Musumeci T, Bonaccorso A, Carbone C, Russo G, Pappalardo F, Puglisi G. Journal of Drug Delivery Science and Technology Design and optimization of PEGylated nanoparticles intended for Berberine Chloride delivery. J Drug Deliv Sci Technol. 2019;52(April):521-30. https://doi.org/10.1016/ j.jddst.2019.05.012.

29. Koroleva MY, Nagovitsina TY, Bidanov DA, Gorbachevski OS, Yurtov EV. Nano- and microcapsules as drug-delivery systems. Resour Technol. 2016;2(4):233-9.

30. Morsy SMI. Role of surfactants in nanotechnology and their applications. Int J Curr Microbiol App Sci. 2014;3(5):237-60.

31. Volić M, Pajić-Lijaković I, Djordjević V, Knežević-Jugović Z, Pećinar I, Stevanović-Dajić Z, et al. Alginate/soy protein system for essential oil encapsulation with intestinal delivery. Carbohydr Polym. 2018;200(July):15-24.

32. Abbasi S, Afrasiabi A, Karimi Zarchi AA, Faramarzi MA, Tavoosidana G, Amani A. Preparation and optimization of Nacetylcysteine nanosuspension through nanoprecipitation: an artificial neural networks study. J Pharm Innov. 2014;9(2):11520.

33. Wang C, Cui B, Guo L, Wang A, Zhao X, Wang Y, et al. Fabrication and evaluation of Lambda-cyhalothrin nanosuspension by one-step melt emulsification technique. Nanomaterials. 2019;9(2):145.

34. Aghbashlo M, Mobli H, Madadlou A, Rafiee S. Fish oil microencapsulation as influenced by spray dryer operational variables. Int J Food Sci Technol. 2013;48(8):1707-13.

35. Mortazavian A, Razavi SH, Ehsani MR, Sohrabvandi S. Principles and methods of microencapsulation of probiotic microorganisms. Iran J Biotechnol. 2007;5(1):1-18.

36. Carbone C, Fuochi V, Zielińska A, Musumeci T, Souto EB, Bonaccorso A, et al. Dual-drugs delivery in solid lipid nanoparticles for the treatment of Candida albicans mycosis. Colloids Surf B: Biointerfaces. 2020;186(December 2019):110705. https:// doi.org/10.1016/j.colsurfb.2019.110705.

37. Sartori GJ, Prado LD, Rocha HVA. Efavirenz dissolution enhancement IV - antisolvent nanocrystallization by sonication, physical stability, and dissolution. AAPS PharmSciTech. 2017;18(8):3011-20.

38. Sohail A, Turner MS, Prabawati EK, Coombes AGA, Bhandari B. Evaluation of Lactobacillus rhamnosus GG and Lactobacillus acidophilus NCFM encapsulated using a novel impinging aerosol method in fruit food products. Int J Food Microbiol. $2012 ; 157$ (2):162-6. https://doi.org/10.1016/ j.ijfoodmicro.2012.04.025. 
39. Ding WK, Shah NP. Survival of free and microencapsulated probiotic bacteria in orange and apple juices. Int Food Res J. 2008;15(2):219-32.

40. Sengun IY, Kirmizigul A, Atlama K, Yilmaz B. The viability of Lactobacillus rhamnosus in orange juice fortified with nettle (Urtica dioica L.) and bioactive properties of the juice during storage. Lwt. 2020;118.

41. 2073/2005 R (EC) N. Commission Regulation (EC) No 2073/ 2005 of 15 November 2005 on microbiological criteria for foodstuffs. Off J Eur Union. 2005;L 338/1-L 338/26.

42. Susanne E. Keller AJM. Microbiological safety of fresh citrus and apple juices. In: Gerald M. Sapers, James R. Gorny AEY, editor. Microbiology of fruits and vegetables. 1st Edition. Boca Raton, Fla, USA: Taylor \& Francis; 2005.
43. Aneja KR, Dhiman R, Aggarwal NK, Kumar V, Kaur M. Microbes associated with freshly prepared juices of citrus and carrots. Int J Food Sci. 2014;2014:1-7.

44. Champagne CP, Gardner NJ. Effect of storage in a fruit drink on subsequent survival of probiotic lactobacilli to gastrointestinal stresses. Food Res Int. 2008;41(5):539-43.

45. Champagne CP, Raymond Y, Gagnon R. Viability of Lactobacillus rhamnosus R0011 in an apple-based fruit juice under simulated storage conditions at the consumer level. J Food Sci. 2008;73(5):221-6.

Publisher's Note Springer Nature remains neutral with regard to jurisdictional claims in published maps and institutional affiliations. 